\title{
Fluorescence in situ hybridization assay detects upper urinary tract transitional cell carcinoma in patients with asymptomatic hematuria and negative urine cytology
}

\author{
W. T. HUANG ${ }^{\ddagger}$, L. Y. LI, J. PANG, X. X. RUAN, Q. P. SUN, W. J. YANG, X. GAO* \\ Department of Urology, The Third Affiliated Hospital, Sun Yat-sen University, Guangzhou, 510630, China \\ ${ }^{*}$ Correspondence: billurology@126.com \\ ${ }^{*}$ Contributed equally to this work.
}

Received October 23, 2011 / Accepted January 11, 2012

\begin{abstract}
We evaluated the performance of a multiprobe FISH (fluorescence in situ hybridization) assay for noninvasive detection of upper urinary tract transitional cell carcinoma (UUT-TCC) in patients with asymptomatic hematuria and negative urine cytology. Voided urine samples from 285 patients with asymptomatic hematuria and negative urine cytology were prospectively analyzed by FISH technique. FISH assays were performed to detect chromosomal changes frequently associated with TCC, including aneuploidy of chromosomes 3, 7 and 17, and loss of the 9p21 locus. Eleven (3.9\%) had a positive FISH result. Of the 11 patients, nine (81.8\%) were found to have a TCC of the upper urinary tract, while no patients with negative FISH findings were found to have UUT-TCC. In this selected cohort, the sensitivity and specificity of FISH for the detection of UUT-TCC was $100 \%$ and $99.3 \%$, respectively. Our preliminary data suggest that the clinical utility of FISH assay of chromosomes 3, 7, 9, and 17 as a noninvasive ancillary test for the diagnosis of UUT-TCC in a selected patient population with asymptomatic hematuria and negative urine cytology and by significant high sensitivity and specificity may be a reliable diagnostic approach for early detection of UUT-TCC patients. Further larger prospective and multicenter trials are needed to confirm our results.
\end{abstract}

Key words: fluorescence in situ hybridization, transitional cell carcinoma, upper urinary tract

Upper urinary tract transitional cell carcinoma (UUTTCC) is an infrequent tumor, with the incidence of $0.7-1.1$ per 100000 people per year, and has increased slightly over the past 30 years. It represents 5-8\% of all patients with transitional cell cancers. Of UUT-TCC, $80 \%$ are detected after a diagnosis of bladder cancer; two thirds of these patients will develop other transitional cell tumors in the future [1].

The most common presenting sign of UUT-TCC is gross or microscopic hematuria. Currently, the evaluation of suspected UUT-TCC included radiographic imaging, cystoscopy combined with urine cytology and ureteroscopy. In addition to risk of concurrent morbidity, radiographic imaging often fails to detect microscopic lesions which may have clinical significance [2]. A voided urine specimen for cytology is the most convenient, least invasive means for establishing the diagnosis of UUT-TCC but with a low sensitivity even under ideal circumstances. The diagnostic rate can be increased with the additional use of ureteroscopy; however, it is an invasive procedure which can be associated with severe complications $[3,4]$.
Early studies demonstrated that multitarget fluorescence in situ hybridization (FISH) analysis for aneuploidy of chromosomes 3, 7 and 17, and loss of the 9p21 locus provided high sensitivity and specificity in the detection of bladder TCC in patients with negative urine cytology and gross or microscopic hematuria $[5,6]$. It has been reported that abnormal karyotypes in UUT-TCC are similar to those found in bladder TCC [7]. However, to our knowledge no study has evaluated the role for multitarget FISH in the detection of UUT-TCC in patients with hematuria and negative urine cytology. The aim of our present study is to assess the utility of FISH as a non-invasive method to detect UUT-TCC in a selected patient population with asymptomatic hematuria and negative urine cytology.

\section{Patients and methods}

Patients. From January 2008 to August 2010, voided urine samples from 285 patients with asymptomatic hematuria and negative urine cytology (148 males and 137 females; mean age 
42.4 years, range $25-83$ ) were prospectively analyzed during evaluation of the upper urinary tract. Of the 285 patients, 261 presented with microscopic hematuria and 24 with gross hematuria. One patient presented with a history of bladder cancer and one with a history of prostate cancer. In addition, 20 voided urines from healthy volunteers with no evidence of urinary tract disorders (11 males and 9 females; mean age 35 years, range 23-57) were analyzed as controls. The study was approved by the hospital's ethical committee and informed consent was obtained from each patient and control.

All 285 patients underwent investigation with cystoscopy and urinary tract imaging, including renal ultrasonography, intravenous pyelography and computed tomography. Five patients underwent also magnetic resonance imaging. Cytologic examination and FISH analysis of the voided urine specimens were performed for all patients. Urine cytology was performed according to Papanicolaus' staining method [8]. None had a positive cystoscopy and urine cytology evaluation. Retrograde pyelography and ureteroscopy were also performed in four patients with suspicion of UUT-TCC. If indicated, surgery (nephroureterectomy with excision of the bladder cuff) was performed.

FISH analysis. Urine samples (at least $200 \mathrm{ml}$ ) were collected the day before starting any treatment for both cytological and FISH analysis. For FISH analysis, samples were placed in centrifuge tubes without preservative or fixative, and were processed within $24 \mathrm{~h}$ after they were shipped. (Fixation of urinary cells was avoided, because the cells must be exposed to hypotonicity for optimal FISH results.) Urine samples were shipped as soon as possible after collection and kept refrigerated until the processing.

Cells from voided urine were centrifuged at $600 \times \mathrm{g}$ for 10 minutes and the cell pellets were harvested with prewarmed potassium chloride hypotonic solution $\left(37^{\circ} \mathrm{C}\right)$ for 20 minutes. This was followed by fixation in Carnoy solution $(3: 1[\mathrm{v} / \mathrm{v}]$ methanol:glacial acetic acid) for 10 minutes $(\times 3)$. Subsequently, $20 \mu \mathrm{l}$ of the final cell pellet suspension was dropped onto a glass slide. Slides were pretreated with a FISH pretreatment kit (GP Medical Technologies, Ltd, Beijing, China) according to the manufacturer's instructions. Then, they were hybridized with the multitarget, dual-color FISH probes. In brief, the final probe mixture consisted of $70 \%$ hybridization buffer solution, $10 \%$ deionized water, $20 \%$ probe DNA. The probes were specific for centromeres of chromosomes 3, 7, 17 and for the p16 (9p21) locus. Two DNA probes were mixed together as a set double-target FISH and paired as follows: chromosome 3 (fluorescein isothiocyanate) and chromosome 7 (rhodamine), chromosome 17 (fluorescein isothiocyanate) and p16 (rhodamine) (GP Medical Technologies, Ltd, Beijing, China).

The slides were cover-slipped, sealed with rubber cement and denatured at $73^{\circ} \mathrm{C}$ for 5 minutes, then hybridized overnight $(16-22 \mathrm{~h})$ at $42^{\circ} \mathrm{C}$ in a humidified chamber. Post hybridization washings were made in $50 \%$ formamide $/ 2 \times$ SSC (standard saline citrate, $\mathrm{pH} 7.0$ ), at $42^{\circ} \mathrm{C}$ for $8 \mathrm{~min}$ - utes $(\times 3)$, in $2 \times$ SSC, for 10 minutes and NP-40 buffer $(2 \times$ $\mathrm{SSC} / 0.1 \% \mathrm{NP}-40$ ) for 10 minutes, then dehydrated by gradient alcohol, and counterstained with with $10 \mu \mathrm{l}$ of DAPI solution (4,6-diamidino-2-phenylindole ).

Samples were evaluated by two independent observers blinded to clinical findings. A minimum of 100 cells from each slide were evaluated. Abnormal signals of nuclei were defined as follows: the counted nuclei present three or more signals for the chromosomes 3, 7, 17 and p16 gene; or the counted nuclei present with a loss of one or two p16 signals. Based on the FISH results of 20 healthy controls, a sample was considered FISH-positive if at least two of the following criteria was met: (1) more than $6.5 \%$ of the counted nuclei present abnormal signals for the chromosome 3; (2) more than $3.9 \%$ of the counted nuclei present abnormal signals for the chromosome 7 ; (3) more than $4.6 \%$ of the counted nuclei present abnormal signals for the chromosome 17 ; (4) more than $3.3 \%$ of the counted nuclei present three or more than three signals for the p16 gene; or (5) more than $12 \%$ of the counted nuclei with a loss of one or two p16 signals. The criteria for FISH positivity were in accordance with those suggested by Halling et al. [9] for the detection of transitional cell carcinomas.

Statistical analysis. The sensitivity, specificity, positive predictive value and negative predictive value of FISH assay as a diagnostic test for UUT-TCC in patients with asymptomatic hematuria and negative urine cytology were calculated respectively.

\section{Results}

Of the 285 patients, 11 (3.9\%) had a positive FISH result. The mean age for these 11 patients was 59.8 years (range $39-78)$. Of the 11 patients, nine (81.8\%) were found to have a TCC of the upper urinary tract (Table 1; Figure 1). Of the 274 patients with negative FISH results, routine investigations included history, physical examination, blood and urine analysis, renal ultrasonography, intravenous pyelography, computed tomography and cystoscopy, which showed no evidence of malignant conditions. None was diagnosed with UUT-TCC after a median followup of 19.8 months (range 2-33) in these 274 patients.

Altogether, of 285 patients with asymptomatic hematuria and negative urine cytology enrolled in this study, 9 were diagnosed to have UUT-TCC. FISH analysis of the voided urine was positive in all these 9 patients. Two cases with positive FISH showed no evidence of UUT-TCC. Of the remaining 274 patients with negative FISH results, none was diagnosed to have UUT-TCC. Thus, the sensitivity of FISH analysis in the detection of UUT-TCC was 100\% (9/9) and specificity $99.3 \%(274 / 276)$ in this cohort. The positive predictive value and negative predictive value were $81.8 \%(9 / 11)$ and $100 \%$ (274/274), respectively.

Of the nine patients who underwent open surgery (nephroureterectomy with excision of the bladder cuff) because of suspected UUT-TCC, all had histologically proven UUT-TCC 

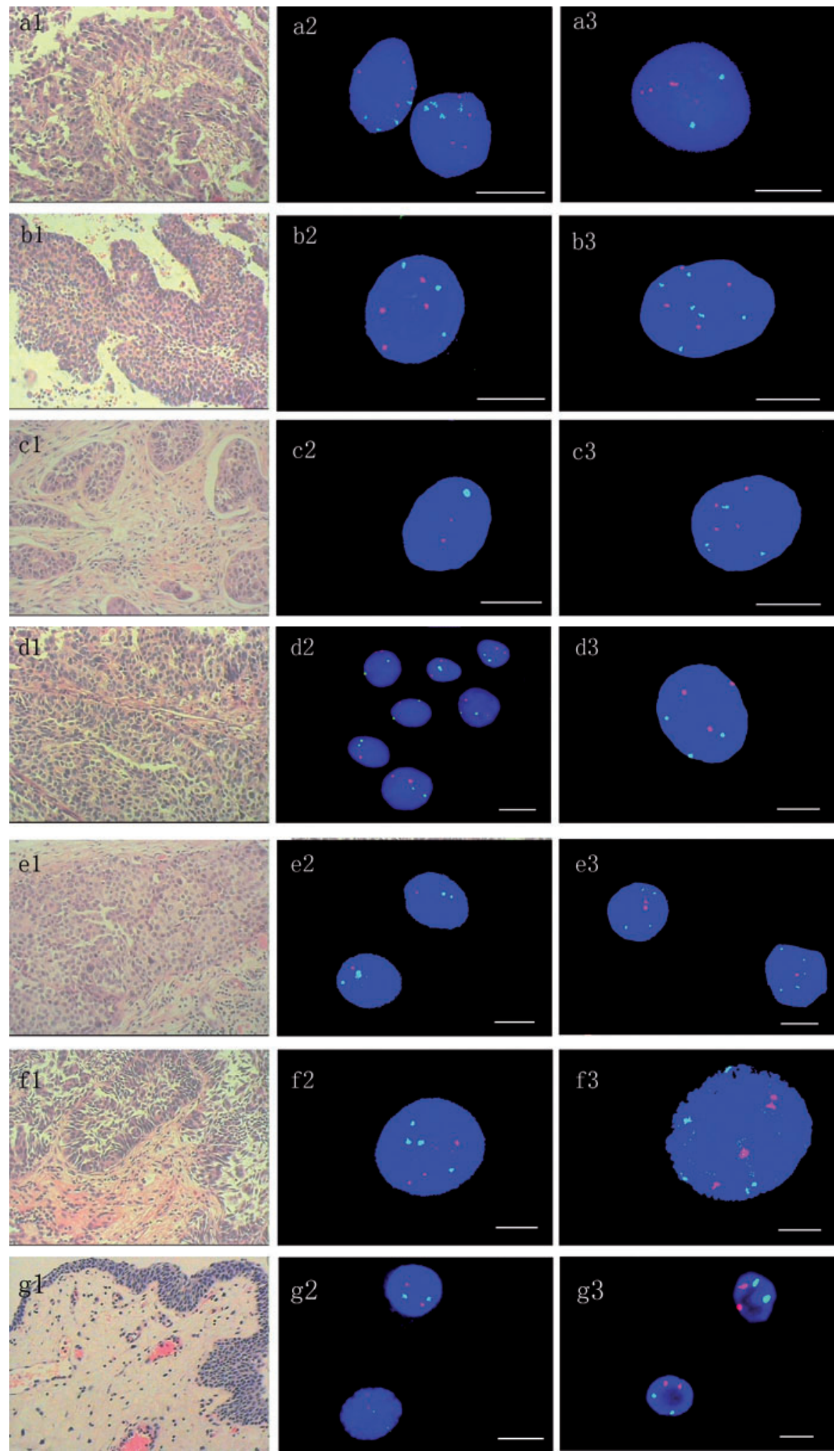

Figure 1. Representative examples of FISH signal patterns from patients with upper urinary tract transitional cell carcinoma (Panels a-f: Pt.1-6 in Table 1) and normal urothelium (Panel g). Postoperative pathological examination demonstrates transitional cell carcinoma (G1-G3, T1-T3) in renal pelvis or ureter (Panels: a1,b1,cl,d1,el,f1). Original magnification of H\&E images, $\times 20$ objective. GLP p16/GLP 17 probe set: p16 (red) and chromosome 17 (green) (Panels: a2,b2,c2,d2,e2,f2,g2); CSP7/CSP3 probe set: chromosome 7 (red) and chromosome 3 (green) (Panels: a3,b3,c3,d3,e3,f3,g3). Abnormal nuclei exhibit three or more signals for the chromosomes 3, 7, 17 and p16 gene or a loss of one or two p16 signals. Panel g2 and g3 are FISH-negative control. Scale bar, $5 \mu \mathrm{m}$. 
Table 1. Clinicopathological data of 11 patients with positive FISH results and negative cytology

\begin{tabular}{|c|c|c|c|c|c|c|c|c|c|c|}
\hline \multirow[b]{2}{*}{$\begin{array}{l}\text { Pt. } \\
\text { No. }\end{array}$} & \multirow[b]{2}{*}{ Sex } & \multirow[b]{2}{*}{ Age } & \multicolumn{5}{|c|}{ FISH (percentages of abnormal signals for chromosomes or gene) } & \multirow[b]{2}{*}{ Cytology } & \multirow[b]{2}{*}{ Location of lesion } & \multirow[b]{2}{*}{ Stage/Grade } \\
\hline & & & $\begin{array}{c}\text { Gain } \\
\text { of } 3\end{array}$ & $\begin{array}{l}\text { Gain } \\
\text { of } 7\end{array}$ & Gain of 17 & $\begin{array}{l}\text { Gain } \\
\text { of p16 }\end{array}$ & $\begin{array}{l}\text { Loss } \\
\text { of p16 }\end{array}$ & & & \\
\hline 1 & Male & $63 y$ & 4 & 23 & 35 & 26 & 7 & Negative & Right Ureter & TCC(pT2G3) \\
\hline 2 & Male & $39 y$ & 29 & 37 & 11 & 6 & 9 & Negative & Right Renal Pelvis & TCC(pT1G1) \\
\hline 3 & Male & $73 y$ & 11 & 19 & 3 & 2 & 6 & Negative & Left Ureter & TCC(pT2G3) \\
\hline 4 & Male & $54 y$ & 9 & 21 & 3 & 1 & 29 & Negative & Right Ureter & TCC(pT1G3) \\
\hline 5 & Male & $64 y$ & 51 & 2 & 4 & 3 & 61 & Negative & Left Renal Pelvis & TCC(pT1G2) \\
\hline 6 & Male & $58 \mathrm{y}$ & 18 & 23 & 41 & 16 & 8 & Negative & Right Renal Pelvis & TCC(pT3G3) \\
\hline 7 & Female & $58 \mathrm{y}$ & 9 & 20 & 5 & 20 & 7 & Negative & No found & No found \\
\hline 8 & Male & $78 y$ & 19 & 5 & 27 & 0 & 11 & Negative & Right Ureter & TCC(pT2G3) \\
\hline 9 & Male & $49 y$ & 15 & 7 & 28 & 4 & 16 & Negative & No found & No found \\
\hline 10 & Male & $55 y$ & 6 & 17 & 11 & 5 & 19 & Negative & Right Ureter & $\mathrm{TCC}(\mathrm{pT} 1 \mathrm{G} 2)$ \\
\hline 11 & Female & $67 y$ & 61 & 22 & 19 & 0 & 52 & Negative & Right Renal Pelvis & $\mathrm{TCC}(\mathrm{pT} 2 \mathrm{G} 3)$ \\
\hline
\end{tabular}

Abbreviations: FISH, fluorescence in situ hybridization; Pt. No., patient number; TCC, transitional cell carcinoma.

(Table 1). In seven patients, the reason for surgery was that ureteroscopic biopsies revealed TCC in upper urinary tract. In the other two cases, nephroureterectomy was performed because of highly suspicious findings on upper urinary tract imaging (computed tomography and magnetic resonance imaging). FISH analysis of the voided urine was true positive in all nine patients. None of the patients with proven UUT-TCC in our cohort had false-negative FISH results.

FISH was positive in one patient with a history of transurethral resection treated bladder cancer (Pt. 4 in Table 1) and one patient with a history of radical prostatectomy for localized pT2a prostate adenocarcinoma (Pt. 3 in Table 1). In these two patients, cytology findings were negative, and ureteroscopic biopsies revealed suspicious lesions in the distal location of right ureter and in the distal location of left ureter, respectively. After nephroureterectomy, pathological findings of the specimens (pT1G3 TCC and pT2G3 TCC, respectively) were in accordance with those ureteroscopic biopsies.

We found no evidence of malignancy in two patients with positive FISH results. The diagnostic workup for these two patients included renal ultrasonography, intravenous pyelography, computed tomography, magnetic resonance imaging, cystoscopy, and ureteroscopy, which presented with negative results and did not yield an indication for surgery. During a close followup of 10 and 32 months respectively, we still found no detectable malignancy in these two patients.

\section{Discussion}

The early diagnosis of UUT-TCC is difficult and the limited number of patients with UUT-TCC makes the organization of randomized, perspective diagnostic trials less likely. Because of low sensitivity, voided urine cytology has been shown to be of little value in the detection of UUT-TCC. Another shortcoming of urine cytology is the great interobserver and intraobserver variation in sensitivity [10]. Ureteroscopy provides a higher sensitivity but this is an invasive technique which can cause severe complications. Besides, it has poor sensitivity in the detection of carcinoma in situ [2].

While various symptoms and signs may be associated with UUT-TCC, hematuria is most typical. Delayed diagnosis of UUT-TCC is common in patients with hematuria and it has been shown to adversely affect patient outcome. Moreover, UUT-TCC often presents at a higher grade and stage compared with bladder TCC, emphasizing the need for early diagnosis [11]. Therefore, a reliable, noninvasive method of detecting UUT-TCC earlier and for monitoring patients with hematuria is urgently needed.

The FDA-approved FISH assay, UroVysion ${ }^{\mathrm{Tm}}$ (Abbott Molecular/Vysis, Des Plaines, IL, USA), is a four-target, multicolor FISH probe set. This UroVysion probe mixture consists of centromeric enumeration probes (CEPs) for chromosomes 3,7 , and 17 , and a locus-specific indicator (LSI) probe to the 9 p21 band that are labeled with red, green, aqua, and gold fluorophores, respectively $[12,13]$. The UroVysion ${ }^{\mathrm{Tm}}$ FISH assay has been increasingly used as a valuable adjunct in detecting and monitoring bladder cancer, not only in cytologically negative, but also in cytologically inconclusive urine samples [5]. Recently, the UroVysion ${ }^{\mathrm{Tm}}$ assay for detecting bladder cancer in patients evaluated for gross or microscopic hematuria was also approved by the FDA [6]. Similar to UroVysion FISH probes design, probes specific for centromeres of chromosomes 3 , 7, 17 and for the p16 (9p21) locus were used in our study. Two DNA probes were mixed together as a set double-target FISH and paired as follows: chromosome 3 (fluorescein isothiocyanate) and chromosome 7 (rhodamine), chromosome 17 (fluorescein isothiocyanate) and p16 (rhodamine) (GP Medical Technologies, Ltd, Beijing, China). Although there may be some difference in fluorescent labeling between our dual-color FISH assay and the multi-color UroVysion FISH test, both assays are performed with the potential to detect the same chromosomal changes frequently associated with TCC, 
including aneuploidy of chromosomes 3, 7 and 17, and loss of the 9p21 locus.

It is reported that upper tract and bladder TCCs are molecularly similar, with $10-15 \%$ of only UUT-TCCs having frequent DNA methylation and microsatellite instability [7]. To date, there are only limited data to reveal the utility of FISH as a non-invasive test in the detection of UUT-TCC. These data suggested that FISH analysis performed on voided urine is feasible and that FISH could provide a reliable and less-invasive ancillary test for the detection of UUT-TCC [14-17]. However, no study has specifically evaluated the role of FISH assay in the detection of UUT-TCC in patients with asymptomatic hematuria and negative urine cytology to date. Our present results showed that with the FISH assay, UUTTCC can be identified with a high specificity and sensitivity in this highly selected patient population with hematuria and negative urine cytology. It is of note that none of the patients with proven UUT-TCC in our cohort had false-negative FISH results. Although Akkad et al. [15] recently reported similar result in their study, the FISH false-negative in our series was remarkably low compared with that (23.3\%) reported by Marin-Aguilera et al. [14]. There are several possible explanations for this finding. Firstly, the patient selection may represent the key to this difference. Our study was designed mainly to determine if there is a role for FISH in the detection of UUT-TCC in a highly selected patient population with asymptomatic hematuria and negative urine cytology. All patients in our study had negative cystoscopy and negative concurrent bladder biopsy if applicable. However, the study of Marin-Aguilera et al included a cohort of 30 consecutive patients initially diagnosed with UUT-TCC. Those with no histologically confirmed tumor were excluded from analysis. Moreover, most of proven TCCs in our cohort were high grade tumors, for which the FISH assay shows higher sensitivity than for low grade tumors [16]. Finally, we did not have long-term followup in our patients. The limited followup time (median, 19.8 months) could explain some of the difference in false negatives as some cancer may have been missed in our study. Future prospective studies will evaluate the issue of false negatives in a larger patient population with longer followup.

FISH was positive in two patients without evidence of TCC and the diagnostic investigations including negative urinary tract imagings, cystoscopy and ureteroscopy did not yield an indication for surgery in our series. Additionally, these two patients showed no evidence of malignancy during a close followup of 10 and 32 months respectively. In bladder TCC, positive FISH results have been shown to precede symptomatic tumor recurrence by several months [18-20]. The term 'anticipatory positives' has been applied to the situation of a FISH-positive result in the absence of concurrent detectable malignancy and this phenomenon was described in many studies of FISH assay for bladder TCC [21,22]. Future studies will be necessary to evaluate the issue of anticipatory positives in FISH assays for the detection of UUT-TCC.
It is of note that our FISH test for samples from healthy volunteers and patients is limited to just four chromosomes ( 3 , 7,9 , and 17), which are among the most frequently altered in UUT-TCC but are not the only ones [23]. Some previous studies have demonstrated a number of frequent genetic changes in TCC, such as increased copy numbers of chromosomes 1 , $3,7,9,11$, and 17 and deletions or total loss of chromosome 9 $[23,24]$. Although a number of probes have been investigated to determine which combination yields the highest sensitivity and specificity for TCC detection, the optimal combination was found to combine CEPs for chromosomes 3, 7, and 17, with a LSI probe to the 9p21 band. This combination significantly increased both the sensitivity and specificity of the assay compared with single probe analysis $[5,6,12,13]$.

In summary, our preliminary results suggest that the clinical utility of FISH assay of chromosomes 3, 7, 9, and 17 as a noninvasive ancillary test for the diagnosis of UUT-TCC in patients with asymptomatic hematuria and negative urine cytology evaluation may be promising. This approach provides significant high sensitivity and specificity in detection in this selected patient population. Further larger prospective and multicenter trials are needed to confirm our results.

Acknowledgements: This study was supported by grants from Program of 5010 of Sun-Yat Sen University (2007028), Key Project of Chinese Ministry of Health, and National Natural Science Foundation of China (30772178).

\section{References}

[1] MUNOZ JJ, ELLISON LM. Upper tract urothelial neoplasms: incidence and survival during the last 2 decades. J Urol 2000; 164: 1523-1525. http: //dx.doi.org/10.1016/S00225347(05)67019-X

[2] MILLS IW, LANIADO ME, PATEL A. The role of endoscopy in the management of patients with upper urinary tract transitional cell carcinoma. BJU Int 2001; 87: 150-162. http: //dx.doi.org/10.1046/j.1464-410x.2001.00992.x

[3] GUARNIZO E, PAVLOVICH CP, SEIBA M, CARLSON DL, VAUGHAN ED JR, et al. Ureteroscopic biopsy of upper tract urothelial carcinoma: improved diagnostic accuracy and histopathological considerations using a multi-biopsy approach. J Urol 2000; 163: 52-55. http: //dx.doi.org/10.1016/S00225347(05)67970-0

[4] LIM DJ, SHATTUCK MC, COOK WA. Pyelovenous lymphatic migration of transitional cell carcinoma following flexible ureterorenoscopy. J Urol 1993; 149: 109-111.

[5] SKACEL M, FAHMY M, BRAINARD JA, PETTAY JD, BISCOTTI CV, et al. Multitarget fluorescence in situ hybridization assay detects transitional cell carcinoma in the majority of patients with bladder cancer and atypical or negative urine cytology. J Urol 2003; 169: 2101-2105. http: //dx.doi.org/ 10.1097/01.ju.0000066842.45464.cC

[6] SAROSDY MF, KAHN PR, ZIFFER MD, LOVE WR, BARKIN $\mathrm{J}$, et al. Use of a multitarget fluorescence in situ hybridization assay to diagnose bladder cancer in patients with hematuria. 
J Urol 2006; 176: 44-47. http: //dx.doi.org/10.1016/S00225347(06)00576-3

[7] FADL-ELMULA I, GORUNOVA L, MANDAHL N, ELFVING P, LUNDGREN R, et al. Cytogenetic analysis of upper urinary tract transitional cell carcinomas. Cancer Genet Cytogenet 1999; 115: 123-127. http: //dx.doi.org/10.1016/ S0165-4608(99)00075-8

[8] MAY M, HAKENBERG OW, GUNIA S, POHLING P, HELKE $\mathrm{C}$, et al. Comparative diagnostic value of urine cytology, UBCELISA, and fluorescence in situ hybridization for detection of transitional cell carcinoma of urinary bladder in routine clinical practice. Urology 2007; 70: 449-453. http: //dx.doi. org/10.1016/j.urology.2007.04.023

[9] HALLING KC, KING W, SOKOLOVA IA, KARNES RJ, MEYER RG, et al. A comparison of BTA stat, hemoglobin dipstick, telomerase and Vysis UroVysion assays for the detection of urothelial carcinoma in urine. J Urol 2002; 167: 2001-2006. http: //dx.doi.org/10.1016/S0022-5347(05)65072-0

[10] LOTAN Y, ROEHRBORN CG. Sensitivity and specificity of commonly available bladder tumor markers vs. cytology: Results of a comprehensive literature review and meta-analyses. Urology 2003; 61: 109-118. http://dx.doi.org/10.1016/S00904295(02)02136-2

[11] STEWART GD, BARIOL SV, GRIGOR KM, TOLLEY DA, MCNEILL SA. A comparison of the pathology of transitional cell carcinoma of the bladder and upper urinary tract. BJU Int 2005; 95: 791-793. http: //dx.doi.org/10.1111/j.1464410X.2005.05402.X

[12] SOKOLOVA IA, HALLING KC, JENKINS RB, BURKHARDT HM, MEYER RG, et al. The development of a multitarget, multicolor fluorescence in situ hybridization assay for the detection of urothelial carcinoma in urine. J Mol Diagn 2000; 2: 116-123. http: //dx.doi.org/10.1016/S1525-1578(10)60625$\underline{3}$

[13] SAROSDY MF, SCHELLHAMMER P, BOKINSKY G, KAHN P, CHAO R, et al. Clinical evaluation of a multi-target fluorescent in situ hybridization assay for detection of bladder cancer. J Urol 2002; 168: 1950-1954. http: //dx.doi. org/10.1016/S0022-5347(05)64270-X

[14] MARIN-AGUILERA M, MENGUAL L, RIBAL MJ, MUSQUERA M, ARS E, et al. Utility of Fluorescence In Situ Hybridization as a Non-invasive Technique in the Diagnosis of Upper Urinary Tract Urothelial Carcinoma. Eur Urol 2007; 51: 409-415. http: //dx.doi.org/10.1016/j.eururo.2006.08.045

[15] AKKAD T, BRUNNER A, PALLWEIN L, GOZZI C, BARTSCH G, et al. Fluorescence in situ hybridization for detecting upper urinary tract tumors-a preliminary report. Urology 2007; 70: 753-757. http: //dx.doi.org/10.1016/ j.urology.2007.06.1103

[16] CHEN AA, GRASSO M. Is there a role for FISH in the management and surveillance of patients with upper tract transitional-cell carcinoma? J Endourol 2008; 22: 1371-1374. http: //dx.doi.org/10.1089/end.2008.0096

[17] LUO B, LI W, DENG CH, ZHENG FF, SUN XZ, et al. Utility of fluorescence in situ hybridization in the diagnosis of upper urinary tract urothelial carcinoma. Cancer Genet Cytogenet 2009; 189: 93-97. http: //dx.doi.org/10.1016/j.cancergencyto .2008 .10 .015

[18] MARIN-AGUILERA M, MENGUAL L, RIBAL MJ, BURSET $\mathrm{M}$, ARCE Y, et al. Utility of a multiprobe fluorescence in situ hybridization assay in the detection of superficial urothelial bladder cancer. Cancer Genet and Cytogenet 2007; 173: 131135. http: //dx.doi.org/10.1016/j.cancergencyto.2006.10.011

[19] LAUDADIO J, KEANE TE, REEVES HM, SAVAGE SJ, HODA RS, et al. Fluorescence in situ hybridization for detecting transitional cell carcinoma: Implications for clinical practice. BJU Int 2005; 96: 1280-1285. http: //dx.doi.org/10.1111/j.1464410X.2005.05826.X

[20] KANG JU, KOO SH, JEONG TE, KWON KC, PARK JW, et al. Multitarget fluorescence in situ hybridization and melanoma antigen genes analysis in primary bladder carcinoma. Cancer Genet and Cytogenet 2006; 164: 32-38. http: //dx.doi. org/10.1016/j.cancergencyto.2005.06.006

[21] YODER BJ, SKACEL M, HEDGEPETH R, BABINEAU D, ULCHAKER JC, et al. Reflex UroVysion testing of bladder cancer surveillance patients with equivocal or negative urine cytology: A prospective study with focus on the natural history of anticipatory positive findings. Am J Clin Pathol 2007; 127: 295-301. http: //dx.doi.org/10.1309/ADJL7E810U1H42BI

[22] LOTAN Y, BENSALAH K, RUDDELL T, SHARIAT SF, SAGALOWSKY AI, et al. Prospective evaluation of the clinical usefulness of reflex fluorescence in situ hybridization assay in patients with atypical cytology for the detection of urothelial carcinoma of the bladder. J Urol 2008; 179: 2164-2169. http: //dx.doi.org/10.1016/j.juro.2008.01.105

[23] STEIDL C, SIMON R, BURGER H, BRINKSCHMIDT C, HERTLE L, et al. Patterns of chromosomal aberrations in urinary bladder tumours and adjacent urothelium. J Pathol 2002; 198: 115-120. http: //dx.doi.org/10.1002/path.1175

[24] ZHAO J, RICHTER J, WAGNER U, ROTH B, SCHRAML $\mathrm{P}$, et al. Chromosomal imbalances in noninvasive papillary bladder neoplasms (pTa). Cancer Res 1999; 59: 4658-4661. 